\title{
Correction to: Kinematic design optimization for anthropomorphic robot hand based on interactivity of fingers
}

\author{
Won Suk You ${ }^{1} \cdot$ Young Hun Lee ${ }^{2} \cdot$ Gitae Kang $^{2} \cdot{\mathrm{Hyun} \mathrm{Seok} \mathrm{Oh}^{2} \cdot \text { Joon Kyue Seo }}^{2} \cdot \mathrm{Hyouk} \mathrm{Ryeol} \mathrm{Choi}^{2}$
}

Published online: 13 March 2019

○) Springer-Verlag GmbH Germany, part of Springer Nature 2019

\section{Correction to: Intelligent Service Robotics https://doi.org/10.1007/s11370-019-00274-x}

The Acknowledgements, not given in the original publication, are as follows.

\section{Acknowledgements}

This research was supported by the convergence technology development program for bionic arm through the National Research Foundation of Korea (NRF) funded by the Ministry of Science \& ICT (No. 2014M3C1B2048175).

Publisher's Note Springer Nature remains neutral with regard to jurisdictional claims in published maps and institutional affiliations.

The original article can be found online at https://doi.org/10.1007/ s11370-019-00274-x.

Hyouk Ryeol Choi

hrchoi@me.skku.ac.kr

1 Mechanical, Industrial, and Manufacturing Engineering,

Oregon State University, Corvallis, USA

2 School of Mechanical Engineering, Sungkyunkwan University, ChunchunDong 300, Jangan-gu, Suwon, Kyungki-do, 440-746, Korea 